\title{
Simulation Modelling of Marine Diesel Engine Cooling System
}

\author{
Tatjana Stanivuka , Branko Lalića, Jelena Žanić Mikuličića, \\ Marko Šundov ${ }^{b}$
}

Every internal combustion engine operates on the principle of converting thermal energy into mechanical work. During fuel combustion in the engine cylinders, the heat is released. It also has its negative effects; one is overheating of the engine cylinders and the engine in general. Since the engine parts are made of metal with its own thermal characteristics, the optimal temperature must be achieved in order to protect the components from overheating and, thus, from undesirable consequences of overheating. For this purpose, cooling medium is used as a means of maintaining the optimum temperature. Keeping the system functional as long as possible and minimizing possible deviations are very complex and difficult tasks. The complexity of the marine cooling system requires finding the optimal modes of operation, which results in an increased use of simulation models. This paper indicates advantages of using system dynamics as a tool for simulating certain events in a very

\section{KEY WORDS}

$\sim$ Marine diesel engine

$\sim$ Cooling system

$\sim$ Simulation

$\sim$ Dynamic mathematical model

\author{
a. University of Split, Faculty of Maritime Studies, Split, Croatia \\ e-mail: tstanivu@pfst.h \\ b. Stano-uprava d.o.o., Split, Croatia \\ e-mail: marko.sundov@stano-uprava.hr \\ doi: 10.7225/toms.v10.n01.008 \\ This work is licensed under (cc) BY
}

Received on: Jan 14, 2021 / Revised on: Mar 9, 2021 / Accepted on: Apr 11, 2021 / Published: Apr 20, 2021 realistic and economically acceptable way to prevent negative consequences for the entire marine system. System dynamics became an indispensable segment of designing various systems as well as the diesel engine cooling system.

\section{INTRODUCTION}

Engine cooling is mandatory. All internal combustion engines must be cooled. With diesel combustion in the engine, only $30 \%$ is converted to usable energy, and exhaust gases generate $35 \%$ of the energy. The engine heats the remaining $35 \%$. This excess heat is a major problem for the engine since it must be removed and additional energy must be expended on the cooling system, which even increases the percentage of net loss (MAN, 2020). These last $35 \%$ are extremely harmful to the engine. The heat should be discharged to the environment as soon as possible and the engine cooled to its normal operating temperature. In addition to these losses, an inadequate cooling system directly threatens the vitality of engine parts, which in the end can significantly reduce shipping market competitiveness. The basic starting point in the development of the cooling method is:

- $\quad$ Effective cooling, i.e. maintaining the required temperature conditions for each part in its cooling circuit regardless of the external temperature conditions;

- How to prevent the effects of seawater on the cooling system, i.e. on the materials and equipment in the cooling circuit (by this is meant corrosion, soiling, galvanic currents action and erosion),

- Economy of cooling system, i.e. reduction of investment, maintenance and necessary costs energy. 
This paper analyses changes in the operation of the MAN$B \& W$ marine diesel engine, type $M C$, by simulating the cooling system of dynamic models. There are some interesting possible scenarios for the operating state of a marine diesel engine cooling system. The validation of a computer model of a marine diesel engine cooling system is performed according to the predefined scenario, which allows simulation of real conditions within the propulsion system itself.

\section{THEORETICAL FRAMEWORK OF DIESEL COOLING SYSTEM IN GENERAL}

The central fresh water cooling system is designed for the main engine, generator diesel engines and other important appliances. The valves of the system are arranged to allow pumps and coolers to be repaired while the plant is running over a spare pump or one cooler, while the other is repaired or regularly maintained. The cooling system is divided into three independent branches: seawater system, low temperature fresh water system LTFW, and high temperature fresh water system HTFW (Milić and Milić, 1995). Two central coolers - fresh water coolers - are provided. Seawater inlet temperature depends on the season and area of navigation, and LTFW inlet temperature is $34^{\circ} \mathrm{C}$ and outlet $44^{\circ} \mathrm{C}$. The cooler panels are made of titanium. Fresh water cooling pipes are seamless. The valve body is cast iron and the internal parts are bronze (Marinesight, 2019). The generator diesel engines are supplied with their own system, and all components such as pump, fresh water cooler, and thermostatic control are included in the specification of the generator engine components (Milić, 1991). The system supply of all generator engines from the common (main) line of the fresh water system is ensured. The fresh water generator engine cooling system is also maintained at constant pressure. The fresh water system of each generator engine can be drained, as needed, into the bilge tank (Lalić et al., 2017).

Four-stroke diesels for electricity production are usually installed in the engine room. The task of the designers in the shipyard is to design and manufacture a unique central cooling system for the ship, taking into account the specifics of both types of diesel engine. From the exposed cooling method it is obvious that the seawater circuit is reduced to the minimum necessary length of the pipeline. It greatly reduces the negative impact of seawater. To prevent excessive temperature at the inlet to individual cylinders, the nominal fresh water temperature in the LP circuit must not exceed $36^{\circ} \mathrm{C}$. Seawater inlet temperature is $32{ }^{\circ} \mathrm{C}$, which is regulated by a thermostatic valve (Hyundai, 2020). For diesel engines running exclusively on heavy fuels, the use of a central cooling system is recommended in order to maintain a constant temperature of the flushing air (Woodyard, 2009). This is not possible by applying a conventional cooling system, where the flushing air is cooled in an air cooler with seawater. Variable temperature depends on the weather conditions and ship's navigation areas (Šretner, 1970; Heywood, 2018).

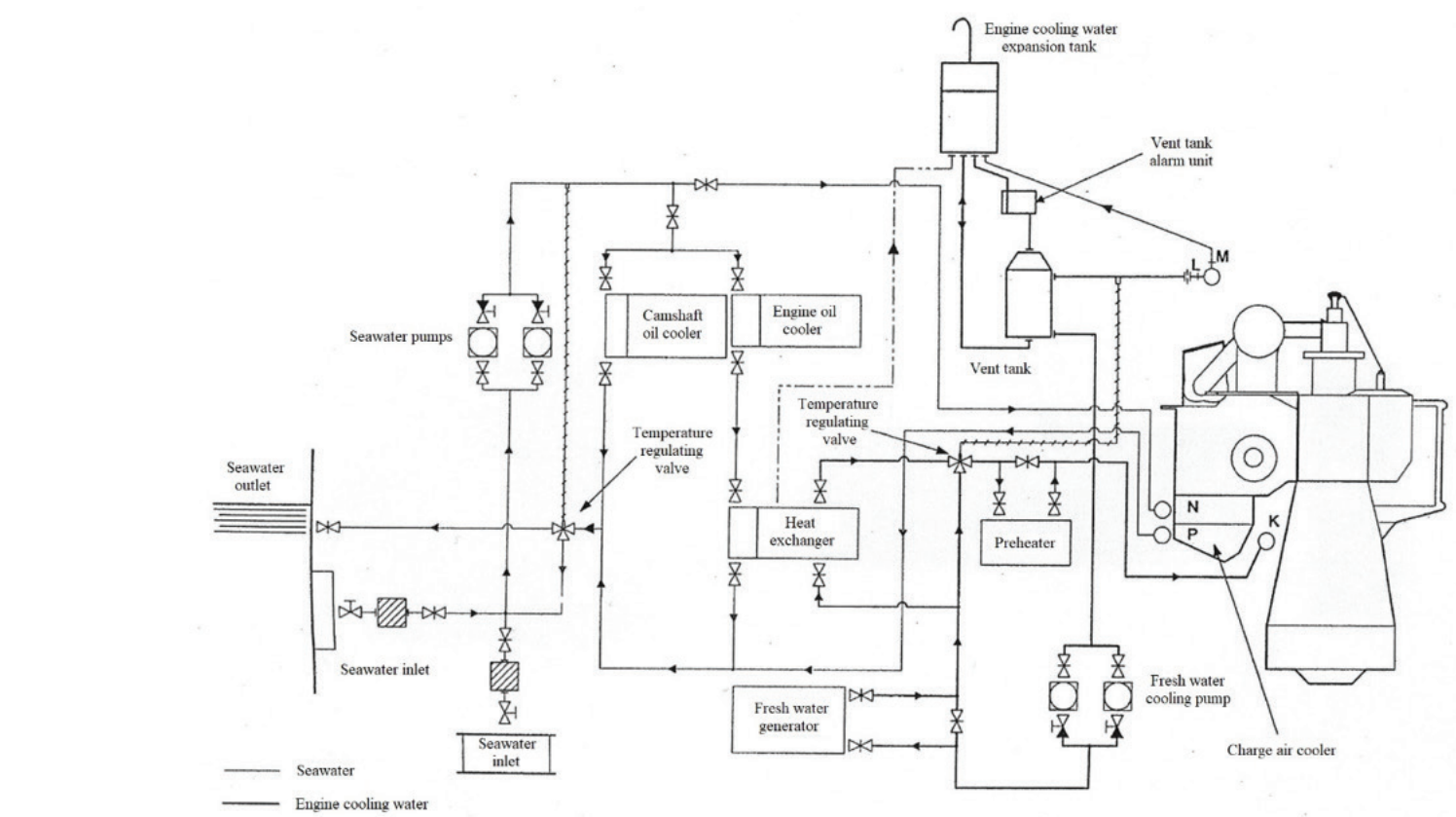

Figure 1.

Scheme of conventional cooling system (Milić, 1991). 
Today, on large ships, marine cooling water is exclusively used for indirect cooling of marine engines (Munitić, 1989). According to the engine manufacturer's instruction book, direct cooling with seawater is excluded for large marine engines (Thiessen and Dales, 1986).

The reason is disadvantage of this cooling type, which is caused by the existence of various impurities in seawater, such as salt and sand. They are part of the engine cooling space and interfere with the heat transfer, i.e. engine cooling. A cooling system was introduced fifty years ago. It foresees a closed fresh water circuit for cylinders of the main and auxiliary diesel engines' cooling (Woodward, 1975; Kongsberg 2015). Other components, i.e. low temperatures continue to cool directly with seawater. It is common to name this cooling system as the conventional one (Figure 1).

\section{Cooling can be done:}

- Directly by seawater, used only for diesel engines of very low power;

- $\quad$ By closed-circuit cooling with fresh water so that fresh water is cooled by seawater. Then, the seawater takes over the heat from the fresh water i.e. conventional cooling (Figure 1);
By cooling in a closed, low temperature circuit with fresh water of all components and the fresh water takes away the heat from the seawater i.e. central cooling (Figure 2).

Figure 2 shows the central cooling system of a two-stroke MAN-B\&W diesel engine, type MC (Kongsberg, 2015). The central fresh water cooling system is divided into two subsystems:

- Low Temperature System,

- High Temperature System.

The Low Temperature Fresh Water (LTFW) system cools all the auxiliary equipment such as:

- Start-air compressors,

- Service air compressor,

- $\quad$ Lubricating oil system for turbo-generator and cargo pump turbines,

- Stern tube and propeller servo oil system,

- Main engine air cooling system,

- Cooling of the oil in the camshaft and main engine lubricating oil system.

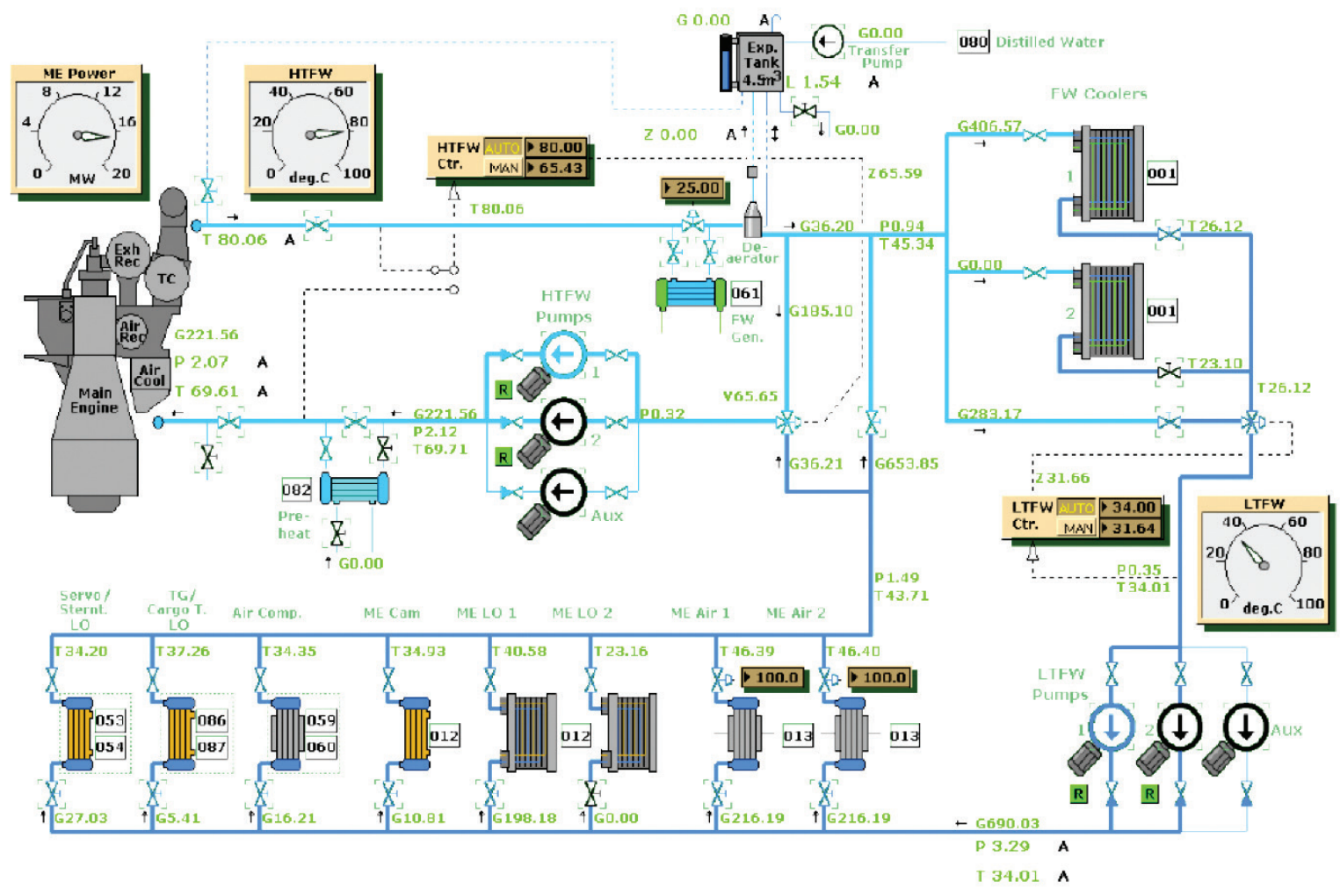

Figure 2 .

Scheme of central cooling system (Kongsberg, 2015), 
The LTFW pumps, normally only one in operation, pump the fresh water through the above mentioned coolers. The FW system is cooled by the SW system. The auxiliary LTFW pump is mainly used when in harbor or during blackout. The fresh water temperature in the LTFW system is controlled by a PID controller, which actuates a three-way mixing valve placed after the two fresh water coolers. This controller can be operated in manual or auto mode. The controller input signal is given by the temperature before the LTFW pumps. From the LT/HT junction, some of the LTFW is led directly to the FW coolers, while some is led to the HTFW loop. The High Temperature fresh water cools the cylinder liners of the main engine. Some of the excessive heat is used for heating the fresh water generator. The fresh water through the main engine is driven by two main and one auxiliary HTFW pumps, of which only one of the main pumps is normally in operation. The auxiliary pump is provided for the use in port. If the HTFW pumps stop, a small cooling medium flow will still be present as long as one of the LTFW pumps is running. If the main engine has been stopped for a long period, it is required to heat the HTFW with the preheater, which is heated with steam. The venting valve in HTFW line after cylinders should always be open. Its purpose is to keep a small amount of water flowing from the cylinders to the expansion tank in order to release the entrapped air in HTFW system. The auxiliary HTFW pump is mainly used when in harbor or during blackout. The HTFW system is controlled by a PID controller, which operates a three-way mixing valve, mixing hot water from main engine outlet with cold water from the LT/ $\mathrm{HT}$ junction. The static pressure in the fresh water system is given by the water level in the fresh water expansion tank. There is a small constant consumption of fresh water due to leakage and evaporation. The expansion tank must be filled periodically.

\section{SIMULATION MODELLING OF THE MARINE DIESEL ENGINE COOLING SYSTEM}

Simulation modelling solves many problems safely and efficiently. It provides an important method of analysis, which is proved, verified and understood (Ljubetić, 2020). It also gives valuable solutions by giving clear insights into complex fields such as diesel engine cooling systems.

System dynamics is an extraordinary software tool for studying dynamics, technical and organizational realities, i.e. systems of different nature and characteristics among which there is a relatively high degree of analogy. However, the term 'simulation' in a broader sense is a series of activities from experimenting on a real system to the analysis of experimental results (Ardakani and Lee, 2018). It means modeling the observed reality, computer programming and experimenting with the model. Simulating events that are possible in some realities is the only way to predict their future mistakes because it would be too dangerous to do any experiments in reality (e.g. ship propulsion). System-dynamic model and simulation regularly use the following techniques (phases) of model making:

- Verbal model that is the result of mental modeling - spoken or written model,

Structural model (diagram of energy and information flows), which is a cause-and-effect relationship of observed system,

- Mathematical model,

- Computer-simulation model made in one of the available software package (Dynamo, Powersim).

\subsection{Dynamic Mathematical Model}

When the static balance between the supply and extract heat is disturbed, the amount of accumulated heat changes in the engine cooling system, which causes a transitional process (Ozretić, 2004). This process is described by the dynamic mode equation

$$
\begin{gathered}
c_{p} \frac{d T_{i}}{d t}=q_{p}-q_{0} \\
c_{p}=c_{v} m_{v}+c_{m} m_{m}
\end{gathered}
$$

where:

$q_{p}$ - specific amount of heat delivered $(\mathrm{J} / \mathrm{kg})$,

$\mathrm{q}_{\mathrm{o}}$ - specific amount of heat dissipated $(\mathrm{J} / \mathrm{kg})$,

$\mathrm{c}_{\mathrm{p}}$ - specific heat capacity of the cooling system $(\mathrm{J} / \mathrm{kgK})$,

$\mathrm{C}_{\mathrm{v}}$ - specific heat capacity of water $(\mathrm{J} / \mathrm{kgK})$,

$\mathrm{C}_{\mathrm{m}}$ - specific heat capacity of the metal $(\mathrm{J} / \mathrm{kgK})$,

$\mathrm{m}_{\mathrm{v}}$ - mass of water in the cooling process $(\mathrm{kg})$,

$\mathrm{m}_{\mathrm{m}}$ - mass of metal involved in the cooling process $(\mathrm{kg})$.

In considering the system dynamics system, the coefficients of heat transfer and the surface through which heat is transferred are taken as constant. It is fully justified if the mass of water circulating through the cooling space is constant (Jurjević, 2001).

The heat exchange between the working fluid and the cylinder wall must be taken into account during the working cycle calculation. Heat is transferred to the walls by convection, and during combustion by radiation. The heat transfer in the cylinder is exposed to the piston crown, inner surface of the cylinder head, and cylinder liner. The exposure of the cylinder liner to heat transfer depends solely on the position of the piston during the operating cycle. During the operating cycle, in the stationary mode, the temperature distribution on the surfaces of the cylinder elements is mostly unchanged, the average surface 
temperature can be calculated (Pflaum and Mollenhauer, 1977; Löhner et al., 1965) so the value of heat transfer to the walls of the combustion chamber is accepted:

$$
\frac{d Q_{s t}}{d a} a_{w} \sum_{i=1}^{n} A_{w i}\left(T_{w i}-T_{s p}\right) \frac{d t}{d a}
$$

The equation for the mean value of the heat transfer coefficient according to Woschni is (Račić, 2008; Lalić, 2020; Woschni, 1970):

$a_{w}=c_{0} \cdot d_{c}^{-2} \cdot p_{c}^{0,8} \cdot T^{0,55} \cdot w^{0,8}$

$W=\left[c_{1} \cdot c_{m}+c_{2} \cdot \frac{V_{s} \cdot T_{c, U Z}}{p_{c, U Z} \cdot V_{c, U Z}} \cdot\left(p_{c}-p_{c K}\right)\right]^{0,8}$

where:

$A_{w i}$ - engine cylinder work surface area $\left(\mathrm{m}^{2}\right)$,

$w$ - average velocity of the gas mixture $(\mathrm{m} / \mathrm{s})$,

$d_{c}$ - cylinder diameter $(\mathrm{m})$,

$p_{c}$-cylinder pressure (bar),

$T_{s p}$ - mean value of gas temperature $(\mathrm{K})$,

$c_{m}=s \cdot n / 60-$ mean piston speed $(\mathrm{m} / \mathrm{s})$.

The constants $C_{1}$ and $C_{2}$ refer to the change in the velocity of the gas mixture during the cycle and are expressed in $\mathrm{m} / \mathrm{s} K$, where the coefficient $\mathrm{CO}$ according to the original expression for the Woschni coefficient for the mean value of heat transfer is $\mathrm{c} 0$ $=130$. As for the coefficient $c 0$ itself, it was shown that it needs to be adjusted in order to achieve the most accurate results. The adjustment can be performed when the Woschni heat transfer coefficient is applied for the purpose of estimating the combustion pressure and calculating the heat transfer (Jianping, 2011; Baratta et al., 2005; Catania et al., 2003; Przybyla et al., 2015; Hairuddin et al., 2013; Parra, 2008; Spitsov, 2013). For the constants $C_{1}$ and $C_{2}$, Woschni proposed their following values (Hardenberg and Hase, 1997): medium,

$C_{1}=6.18+0.417 \cdot C_{v r} / C_{m}$ - during the change of the working

$$
\mathrm{C}_{1}=2.28+0.308 \cdot \mathrm{C}_{\mathrm{vr}} / \mathrm{C}_{\mathrm{m}} \text { - during compression and }
$$
expansion,

$C_{2}=0.00324$ - for direct injection diesel engines,

where: $\mathrm{c}_{\mathrm{vr}}$ - mean swirling flow of a mixture of gases $(\mathrm{m} / \mathrm{s})$,

$c_{m}$ - mean piston speed $(\mathrm{m} / \mathrm{s})$.

The amount of heat transferred can be simplified with the following formula

$q_{p}=a \cdot A \cdot\left(T_{p}-T_{i}\right)$

where:

$a$ - heat transfer coefficient $\left(\mathrm{W} / \mathrm{m}^{2} \mathrm{~K}\right)$,

$A$ - engine cylinder work surface area $\left(\mathrm{m}^{2}\right)$.

The expression (3) is represented by a simplified formula (6) as a function gas temperature $\left(T_{p}\right)$ and regulated water temperature $\left(T_{i}\right)$ at the outlet of the engine.

$q_{p}=f\left(T_{p} ; T_{i}\right)$

The functional dependence of the heat dissipated is given in accordance with the regulation possibilities. The heat dissipated $\left(q_{0}\right)$ can be represented by the formula

$q_{0}=c_{v} \cdot m \cdot s \cdot\left(T_{i}-T_{x}\right)$

where:

$s$ - coordinate of the control element

$T_{x}$ - water temperature from the cooler $(\mathrm{K})$,

$T_{i}$ - water temperature at the engine outlet (K).

In agreement with equation (1)

$q_{0}=f\left(s ; T_{i} ; T_{x}\right)$

after linearizing expressions (1) and (2) and incorporating them into (2) taking into account the equilibrium conditions, the equation of the dynamic mode of the cooling system is achieved

$c_{p} \cdot \frac{d \Delta T}{d t}+\left[\left(\frac{\partial q_{0}}{\partial T_{i}}\right)_{0}-\left(\frac{\partial q_{p}}{\partial T_{i}}\right)_{0}\right] \cdot \Delta T_{i}=$

$\left(\frac{\partial q_{p}}{\partial T_{p}}\right)_{0} \cdot \Delta T_{p}-\left(\frac{\partial q_{0}}{\partial s}\right) \cdot \Delta s-\left(\frac{\partial q_{0}}{\partial T_{x}}\right)_{0} \cdot \Delta T_{x}$ 
where:

$$
f_{v}=\left[\left(\frac{\partial q_{0}}{\partial T_{i}}\right)_{0}-\left(\frac{\partial q_{p}}{\partial T_{i}}\right)_{0}\right]-\text { stability factor. }
$$

A system-dynamic qualitative structural model for the high temperature water-cooling subsystem and a high temperature control models are explained through the mathematical model of corresponding cooling system and the cooling water temperature controller.

By dividing equation (8) by the factor of stability $\left(f_{v}\right)$, introducing relative quantities and using the index ' $\mathrm{o}$ ' for the equilibrium values and ' $r$ ' for the reference values, the following is obtained:

$T_{0} \cdot \frac{d Y_{i}}{d t}+Y_{i}=K_{p} \cdot Y_{p}-K_{s} \cdot Y_{s}-K_{x} \cdot Y_{x}$ where:

$$
\begin{aligned}
& Y_{i}=\frac{\Delta T_{i}}{t_{i, r}} ; \quad Y_{p}=\frac{\Delta T_{p}}{t_{p, r}} ; Y_{s}=\frac{\Delta s}{s_{r}} ; Y_{x}=\frac{\Delta T_{x}}{t_{x}} ; \\
& T_{0}=\frac{c_{p}}{f_{v}} ; \quad K_{p}=\frac{\left(\frac{\partial a_{p}}{\partial T_{p}}\right)_{0}}{f_{v}} \cdot \frac{T_{p \cdot r}}{T_{i, r}} ; \quad K_{s}=\frac{\left(\frac{\partial a_{v}}{\partial s}\right)_{0}}{f_{v}} \cdot \frac{s_{r}}{T_{i, r}} ; \quad K_{x}=\frac{\left(\frac{\partial q_{0}}{\partial T_{x}}\right)_{0}}{f_{v}} \cdot \frac{T_{x \cdot r}}{T_{i, r}} ;
\end{aligned}
$$

Figure 3 shows a diagram of a simplified central marine diesel engine cooling system. The scheme shows certain cooling systems of a marine diesel engine with characteristic values and locations where one regulates the sizes essential for further simulation of processes within the system. According to the scheme shown in Figure 3, there are 4 types of heat exchangers in which heat is exchanged between different media.

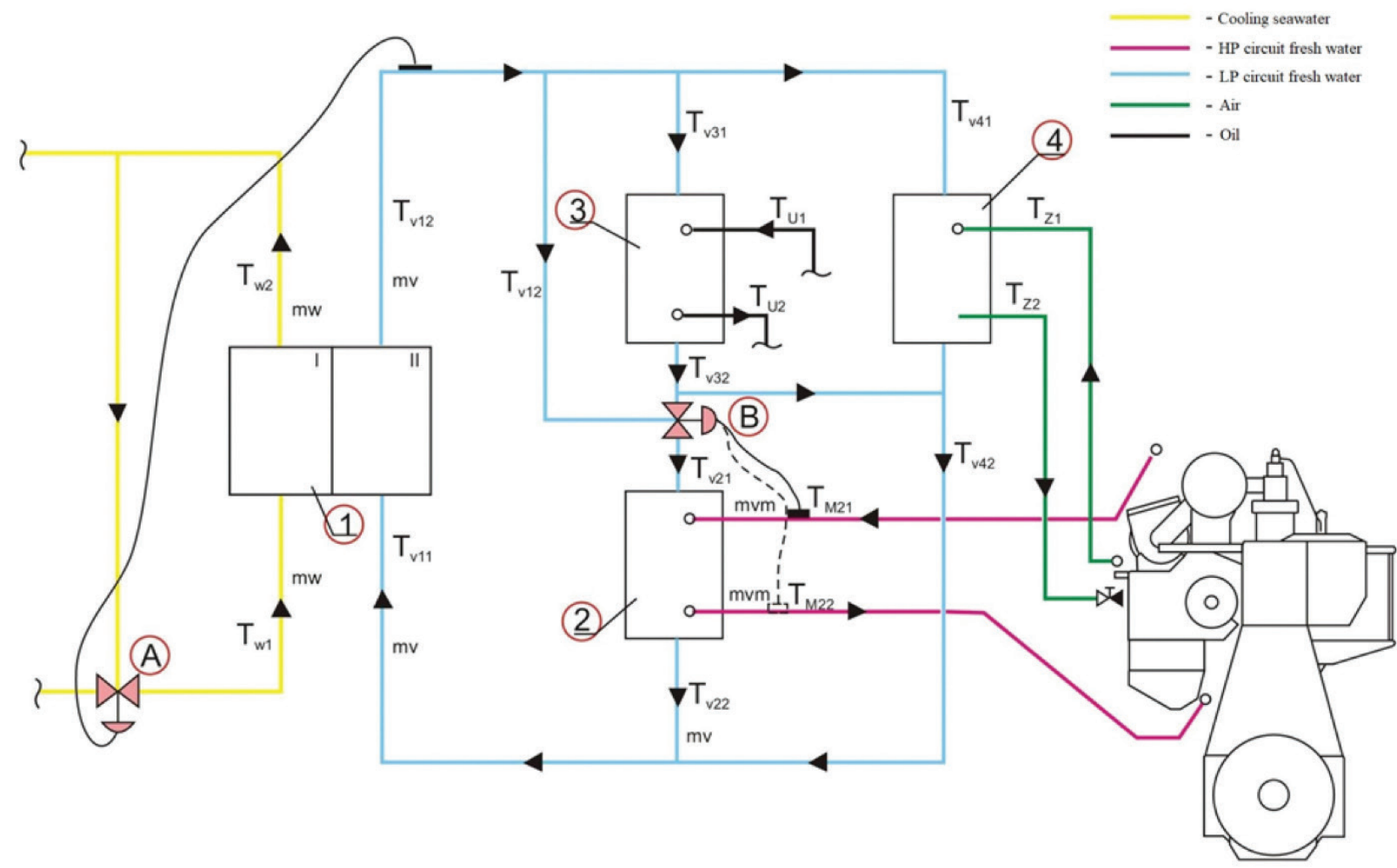

Figure 3.

Scheme of a simplified central diesel engine cooling system (Authors).

where:

1 - central cooler (cools fresh water of LP circuit with seawater),

2 - HP fresh water circuit cooler (it cools fresh water to cool cylinders),
3 - oil cooler,

4 - air cooler

$\mathrm{TW}_{1}$-seawater temperature at, the inlet of the cooler 1 ,

$\mathrm{TW}_{1}$-seawater temperature at the outlet of the cooler 1, $\mathrm{TV}_{11}$-LP fresh water temperature at inlet to cooler 1, 
1 ,

$\mathrm{TV}_{12}$ - LP fresh water temperature at the outlet of the cooler

$\mathrm{TV}_{21}$ - LP fresh water temperature at inlet 2,

$\mathrm{TV}_{22}$ - LP fresh water temperature at the outlet of cooler 2,

$\mathrm{TV}_{31}$ - LP fresh water temperature at inlet 3 ,

$\mathrm{TV}_{32}$ - LP fresh water temperature at outlet 3 ,

$\mathrm{TV}_{41}$ - LP fresh water temperature at inlet 4,

$\mathrm{TV}_{42}$ - LP fresh water temperature at the cooler outlet 4,

$\mathrm{TM}_{21}$ - HP circuit fresh water temperature at engine outlet and cooler inlet 2 ,

$\mathrm{TM}_{22}-\mathrm{HP}$ circuit fresh water temperature at engine inlet and cooler outlet 2 ,

$\mathrm{TU}_{1}$ - oil inlet temperature 3 ,

$\mathrm{TU}_{2}$ - oil temperature at the outlet of the cooler 3,

$\mathrm{TZ}_{1}$ - air inlet temperature 4,

$\mathrm{TZ}_{2}$ - air temperature at the outlet of the cooler.

Since the temperature values must be regulated, two values have been selected: the fresh water temperature of the LP circuits at the cooler outlet $1\left(\mathrm{TV}_{12}\right)$, and the fresh water temperature of the HP circuits at the engine outlet and cooler inlet $2\left(\mathrm{TM}_{21}\right)$. Whether the heat exchange is sea-fresh water, fresh water-oil, fresh water-air or fresh water-fresh water, there is always a certain temperature value to be regulated (Lalić et al., 2014). For this reason, two values are chosen for further analysis:

- Fresh water temperature of the LP circuit at the outlet of the cooler $1\left(\mathrm{TV}_{12}\right)$,

- $\quad$ Fresh water temperature HP circuit at the outlet of the engine and the inlet to the cooler $2\left(\mathrm{TM}_{21}\right)$.

To do this, the control elements at the points $A$ and $B$ are to be set. The dynamic model of heat transfer and dissipation in the space of the cooler 2 (HP fresh water circuit cooler) can be expressed by the following expression:

$C_{2} \cdot \frac{d \Delta T_{M 21}}{d t}=Q_{p}-Q_{0}$

The static regime assumes the equilibrium state of the control object and there is no change if the input and output quantities of energy are equal (11). The cooling process of diesel engines occurs according to a static characteristic in which the amount of heat supplied is equal to the heat exhaust. The temperature of the cooled medium is approximately constant. Static characteristics can be presented by formulas, tables and diagrams, and can be linear or nonlinear. The static model of heat transfer and dissipation in the space of the cooler 2 (HP fresh water circuit cooler) can be expressed by the following expression:
$Q_{p}-Q_{o}=0$

$Q_{p}=f\left(T_{p^{\prime}}, T_{M 21}\right) ; Q_{0}=f\left(T_{M 21}, T_{M 22}\right)$

where:

$C_{2}$ - specific heat capacity of the cooler $2(\mathrm{~J} / \mathrm{kgK})$,

$Q_{p}$ - heat delivered in the cooler $2(\mathrm{~J})$,

$Q_{o}$ - heat dissipated in the cooler $2(\mathrm{~J})$,

$T M_{21}$ - HP circuit fresh water temperature at engine outlet and cooler inlet $2(\mathrm{~K})$,

$T M_{22}$ - HP circuit fresh water temperature at engine inlet and cooler outlet $2(\mathrm{~K})$,

$T_{p}$ - function gas temperature $(\mathrm{K})$.

According to Mac Lauren series and linearizing, the differential equation of high temperature engine cooling is achieved:

$T_{M} \cdot \frac{d x_{M 2}}{d t}+X_{m_{2}} K_{p} \cdot Y_{p}-K_{22} \cdot Y_{22}$

where:

$\mathrm{T}_{\mathrm{m}}$ - time constant related to cooler $2(\mathrm{~K})$,

$\mathrm{X}_{\mathrm{m} 2}=\Delta \mathrm{TM}_{21} / \mathrm{TM}_{21}-\mathrm{O}$ - relative change in water temperature at engine outlet and radiator inlet 2 ,

$\mathrm{K}_{\mathrm{p}}$ - gain coefficient according to the gas temperature in the engine cylinder, cylinder

$Y_{p}$ - relative change in gas temperature in the engine

$\mathrm{K}_{22}$ - gain coefficient according to fresh water temperature $\mathrm{HP}$ circuit at the cooler outlet 2 and the engine inlet,

$Y_{22}$ - relative change in fresh water temperature of the HP circuit at the cooler outlet 2 and the engine inlet.

\subsubsection{Cooler 1 (Central Cooler)}

This cooler is considered as two-part and two-capacity heat exchanger, in which heat is accumulated. In space II (LP fresh water space) heat is supplied from the oil cooler 3, the HP fresh water cooler 2 and the air cooler 4 . An equal value of thermal conductivity coefficients is expected. It depends only on the water circulation speed in both spaces (I and II). Dynamic model of heat delivery and dissipation in the space of the central cooler 1 can be expressed by the following expression: 
$C_{1} \cdot \frac{d t_{v 12}}{d t}=Q_{1 d}-Q_{10}$

where:

$C_{1}$ - specific heat capacity of the central cooler $(\mathrm{J} / \mathrm{kgK})$,

$Q_{1 d}$ - amount of heat brought to the central cooler $(\mathrm{J})$,

$Q_{10}$ - amount of heat removed from the central cooler $(\mathrm{J})$,

$T V_{12}$ - regulated temperature at the cooler outlet $1(\mathrm{~K})$.

The static model of heat delivery and dissipation in the space of the cooler 1 (central cooler) can be expressed by the following expression:

$Q_{1 p}-Q_{10}=0$

$Q_{1 p}=f\left(T_{v 11}, T_{v 12}\right) ; Q_{10}=f\left(T_{v 11}, T_{v 12}, T_{w 1}, T_{w 2}, G_{A}\right)$

where:

$Q_{1 p}$ - heat delivered in the cooler $1(\mathrm{~J})$,

$Q_{10}$ - heat dissipated in the cooler $1(\mathrm{~J})$,

$T V_{11}$ - LP fresh water temperature at inlet to cooler $1(\mathrm{~K})$,

$T W_{1}$ - seawater temperature at the inlet of the cooler $1(\mathrm{~K})$,

$T W_{2}$ - seawater temperature at the outlet of the cooler $1(\mathrm{~K})$,

$G_{A}$ - relative change in the opening of valve $A$ at the seawater inlet into cooler 1.

Developing $Q_{10}$ and $Q_{1 p}$ in Mac Lauren order and linearizing it, the differential equation for cooler 1 is obtained:

$T_{01} \cdot \frac{d x_{1}}{d t+x_{1}}=K_{21} \cdot Y_{21}+K_{31} \cdot Y_{31}-K_{41} \cdot Y_{41}-K_{A} \cdot G_{2 A}$

where:

$T_{01}$ - time constant related to cooler 1 ,

$X_{1}$ - relative change in fresh water temperature of LP circuit at cooler outlet 1 ,

$K_{21}$ - gain coefficient according to fresh water temperature of LP circuit at cooler inlet 1 ,

$Y_{21}$ - relative change in fresh water temperature of LP circuit at cooler inlet 1 ,
$K_{31}$ - reinforcement coefficient according to seawater temperature at the cooler inlet 1 , inlet 1,

$Y_{31}$ - relative change in seawater temperature of cooler

$K_{41}$ - gain coefficient according to the temperature of seawater at cooler inlet 1 ,

$Y_{41}$ - relative change in seawater temperature at cooler outlet 1,

$K_{A}$ - gain coefficient according to the degree of openness,

$G_{A}$ - relative change of valve $A$ opening at the seawater inlet into cooler 1.

\subsubsection{Cooler 2 (Fresh Water HP Cooler)}

The static model of heat delivery and dissipation in the space of the cooler 2 (HP fresh water circuit cooler) can be expressed by the following expression:

$Q_{2 p}-Q_{20}=0$

$Q_{0}=Q_{2 p}=f\left(T_{M 21}, T_{M 22}\right) ; Q_{20}=f\left(T_{M 21}, T_{M 22}, T_{V 21}, T_{V 22}, G_{B}\right)$

where:

$Q_{2 p}$ - heat delivered in the cooler $2(\mathrm{~J})$,

$Q_{20}$ - heat dissipated in the cooler $2(\mathrm{~J})$,

$T_{21}$ - HP circuit fresh water temperature at engine outlet and cooler inlet $2(\mathrm{~K})$,

$T M_{22}-\mathrm{HP}$ circuit fresh water temperature at engine inlet and cooler outlet $2(\mathrm{~K})$,

$T V_{21}$ - LP fresh water temperature at the inlet $2(\mathrm{~K})$,

$T V_{22}$ - LP fresh water temperature at the outlet of cooler $2(\mathrm{~K})$,

$G_{B}$ - relative change in openness of valve B to seawater inlet of LP circuit in cooler $2(\mathrm{~K})$.

The dynamic model of heat delivery and dissipation in the space of the cooler 2 (HP fresh water circuit cooler) can be expressed by the following expression:

$C_{2} \cdot \frac{d T_{M 12}}{d t}=Q_{2 p}-Q_{20}$ 
After developing Mac Lauren series, linearizing it and introducing dimensionless replacements, the equation for the dynamic mode of the cooler 2 is achieved:

$T_{02} \cdot \frac{d x_{2}}{d t}+X_{2}=K_{22} \cdot Y_{22}+K_{32} \cdot Y_{32}-K_{42} \cdot Y_{42}-K_{B} \cdot G_{B}$

where:

$T_{O 2}$ - time constant related to cooler 2 ,

$\mathrm{X}_{2}$ - relative change in water temperature of the HP circuit at the cooler outlet 2 and the engine inlet,

$K_{22}$ - gain coefficient to the fresh water temperature at engine outlet and cooler inlet 2 ,

$Y_{22}$ - relative change in fresh water temperature of the HP circuit at the cooler outlet 2 ,

$K_{32}$ - gain coefficient according to fresh water inlet temperature 2,

$Y_{32}$ - relative change in fresh water temperature of LP circuit at the inlet 2,

$K_{42}$ - gain coefficient according to fresh water temperature of LP circuit at cooler outlet 2,

$Y_{42}$ - relative change in fresh water temperature of NT circuit at cooler outlet 2 ,

$K_{B}$ - gain coefficient according to the degree of openness of thermo-regular valve $B$.

\subsubsection{Static Mode}

Further elaboration of static operating modes leads to the following equations for the calculation of individual values of the dynamic mathematical model of central cooling of a marine diesel engine. The equation of proportional seawater flow regulator

$G_{A}=K_{10} \cdot X_{1}$

holds that the coefficient $K_{10}$ and the relative change in valve $A$ opening $\left(G_{A}\right)$ increases. If the relative change in the fresh water temperature of the LP circuit at the cooler 1 outlet increases $\left(\mathrm{X}_{1}=\Delta \mathrm{TV}_{12} / \mathrm{TV}_{12-\mathrm{o}}\right)$, the relative change in the valve $\mathrm{A}$ opening $\left(G_{A}\right)$ also increases.
$Y_{41}=K_{A} \cdot G_{A}$

\section{The equation of proportional HP circuit controller}

$G_{B}=K_{11} \cdot X_{2}$

holds that if the gain coefficient increases according to the degree of the thermostatic regulating valve $B$ opening $\left(\mathrm{K}_{11}\right)$, the relative change of valve $B$ opening of seawater LP circuit at the cooler 2 inlet $\left(G_{B}\right)$ also increases. If the relative change of freshwater temperature of the HP circuit at the cooler 2 outlet increases $\left(X_{2}=\Delta T M_{22} / T M_{22-o}\right)$, the relative change in valve $B$ opening $\left(G_{B}\right)$ also increases.

For the relative change in gas temperature

$G_{p}=0,5 \cdot P_{e}$

it is true that if the engine power $\mathrm{P}_{\mathrm{e}}$ increases, the relative change of the gas temperature in the cylinder also increases $\left(\mathrm{Y}_{\mathrm{p}}=\Delta \mathrm{T}_{\mathrm{p}} / \mathrm{T}_{\mathrm{p}-\mathrm{o}}\right)$.

For the relative temperature change at the cooler inlet 1

$Y_{21}=K_{12} \cdot Y_{42}$

it is true that if gain coefficient increases according to freshwater temperature of LP circuit at the cooler inlet $2\left(\mathrm{~K}_{12}\right)$, the relative change in fresh water temperature of $\mathrm{L}_{\mathrm{p}}$ circuit at the cooler outlet $2\left(\mathrm{Y}_{42}=\Delta \mathrm{TV}_{22} / \mathrm{TV}_{22-\mathrm{o}}\right)$ also increases.

For the relative change in seawater temperature at the cooler outlet 1

it is true that if the gain coefficient increases according to the degree of valve $A$ opening $\left(K_{A}\right)$, the relative change in the valve $A$ opening at the cooler inlet $1\left(G_{A}\right)$ also increases. 


\subsection{Structural Model}

After developing a dynamic mathematical model of the systems observed, a dynamic qualitative model of that system is made (Kongsberg, 2015). For the high-temperature cooling circuit, mathematical (17) and structural models are made (Figure 4):

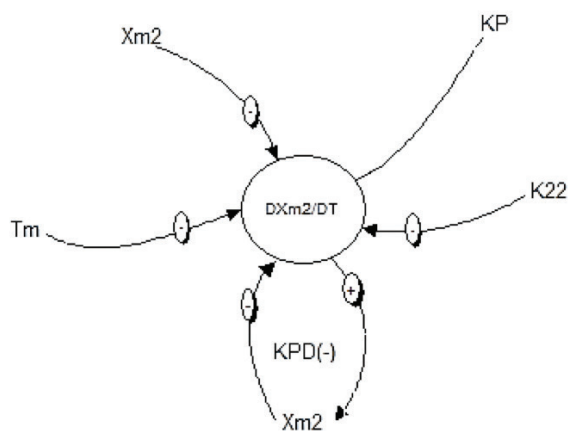

Figure 4.

Dynamic qualitative structural model of high temperature cooling circuit (Authors).

For the cooler 1, which has a mathematical model according to expression (15), there is also a structural model (Figure 4):

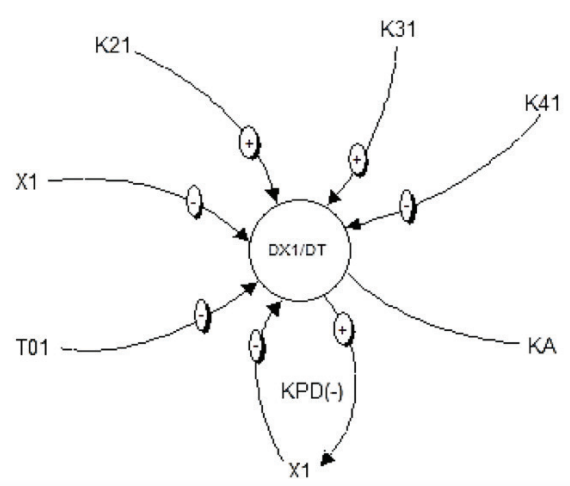

Figure 5.

Dynamic qualitative structural model of cooler 1 (Authors).

For the cooler 2, which has a mathematical model according to expression (18), there is also a structural model (Figure 6):

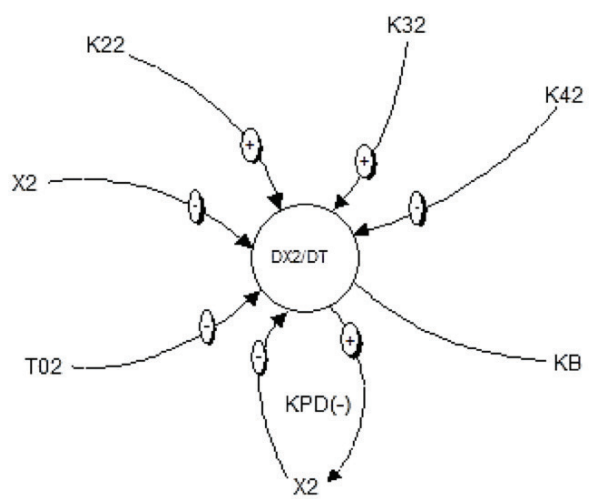

Figure 6.

Dynamic qualitative structural model of cooler 2 (Authors).

For the proportional seawater flow controller shown in expression (19), there is also a structural model (Figure 7):

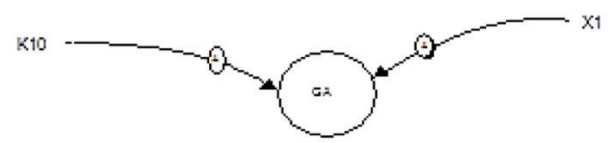

Figure 7.

Dynamic qualitative structural model related to the seawater flow controller (Authors).

For the proportional controller of the HP circuit shown in expression (20), there is also a structural model (Figure 8):

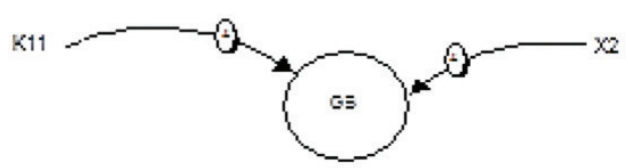

Figure 8.

Dynamic qualitative structural model related to the proportional controller of the HP circuit (Authors).

For the relative change of the fresh water temperature at the cooler inlet 1, shown in expression (22), there is also a structural model (Figure 9): 


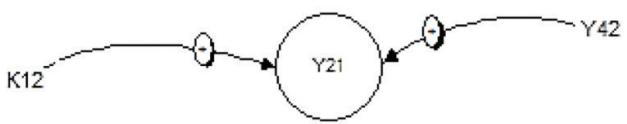

Figure 9.

Dynamic qualitative structural model related to the relative change in fresh water temperature at the cooler inlet 1 (Authors).

For the relative change in the temperature of the gases depending on the load, shown in expression (21), there is also a structural model (Figure 10):

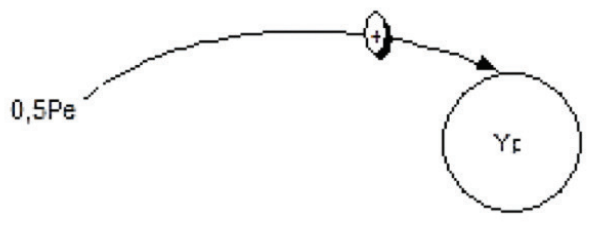

\section{SIMULATION MODELLING OF THE MARINE DIESEL ENGINE COOLING SYSTEM}

Based on the developed systems of dynamic mathematical models, mental-verbal and structural models, there is also a system of dynamic flow diagram of the observed marine diesel engine cooling system (Grzadziela et al., 2017). Based on the given equations of individual systems, it is possible to determine the mathematical simulation model (Figure 11) represented by the explicit form of a set of nonlinear differential equations:

$$
\frac{d x m_{2}}{d t}=\frac{1}{T m} \cdot\left(-X m_{2}+K_{p} \cdot Y_{p}-K_{22} \cdot Y_{22}\right)
$$

from which follows

$$
\frac{d x_{1}}{d t}=\frac{1}{T_{01}} \cdot\left(-X_{1}+K_{21} \cdot Y_{21}+K_{31} \cdot Y_{31}-K_{41} \cdot Y_{41}-K_{A} \cdot G_{A}\right)
$$

and

$$
\frac{d x_{2}}{d t}=\frac{1}{T_{02}} \cdot\left(-X_{2}+K_{22} \cdot Y_{22}+K_{32} \cdot Y_{32}-K_{42} \cdot Y_{42}-K_{B} \cdot G_{B}\right)
$$

Figure 10.

Dynamic qualitative structural model related to the relative temperature change of gases depending on the motor load (Authors).

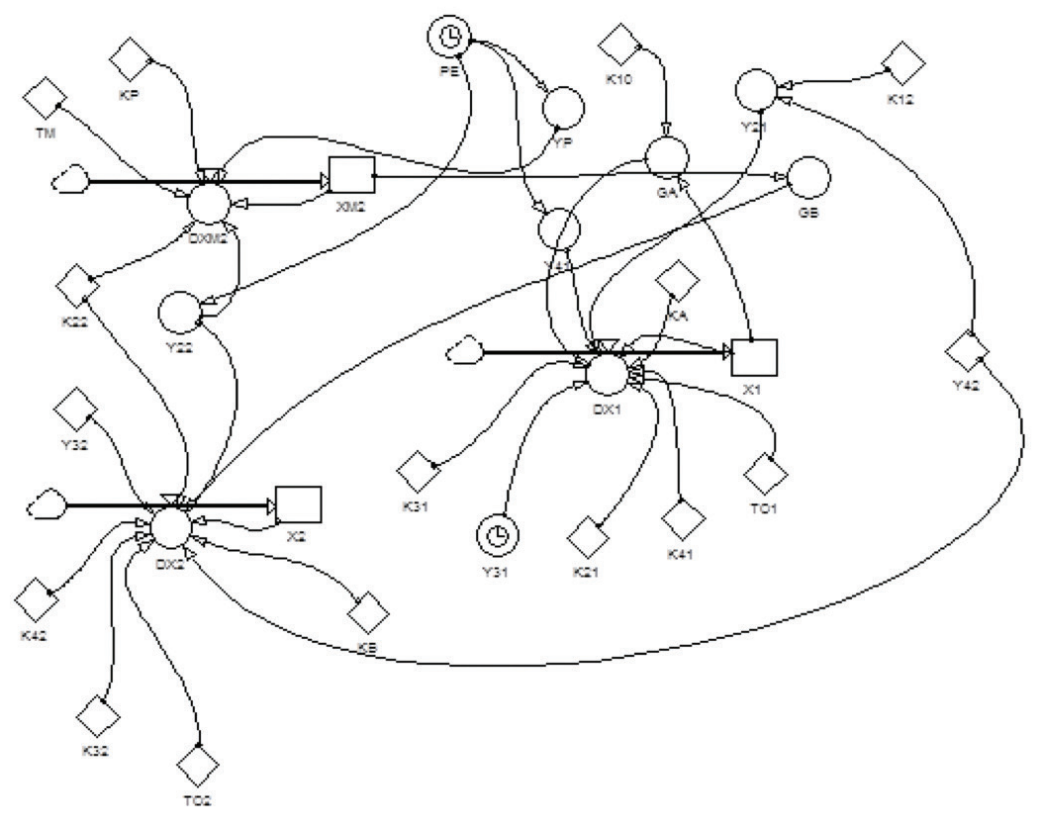

Figure 11.

Global model of marine diesel engine cooling system in Powersim symbols (Authors). 
One of a number of interesting possible scenarios for the operating state of a marine diesel engine cooling system is eliminated. The validation of a computer model of a marine diesel engine cooling system was performed according to the following scenario: engine power changes up to 40 seconds, and in the 40 seconds there is a $30 \%$ change in load according to the bounce function (Figure 12). This power is kept up to 55 seconds, when the power changes according to the impulse function by $25 \%$, and it remains unchanged (Figure 13). Also relative value of the HP circuit fresh water temperature changes at the outlet of the cooler 2 and the engine inlet (Figure 14). By using Powersim language program, based on the initial values of variables and parameters given in the model itself, the following numerical data was obtained in the time interval from 0 to 90 seconds, i.e. the values of time constants:

$$
\begin{aligned}
& \mathrm{K}_{21}=0,25 ; \mathrm{K}_{31}=0,001 ; \mathrm{K}_{32}=0,1 ; \mathrm{K}_{11}=0,01 ; \mathrm{K}_{41}=0,01 ; \mathrm{K}_{\mathrm{p}}=0,1 ; \\
& \mathrm{K}_{42}=0,1 ; \mathrm{K}_{10}=0,01 ; \mathrm{K}_{\mathrm{A}}=0,1 ; \mathrm{K}_{22}=0,015022 ; \mathrm{K}_{\mathrm{B}}=0,1 .
\end{aligned}
$$

The diagrams show the response to defined changes in engine power for each part of the system (subsystem).

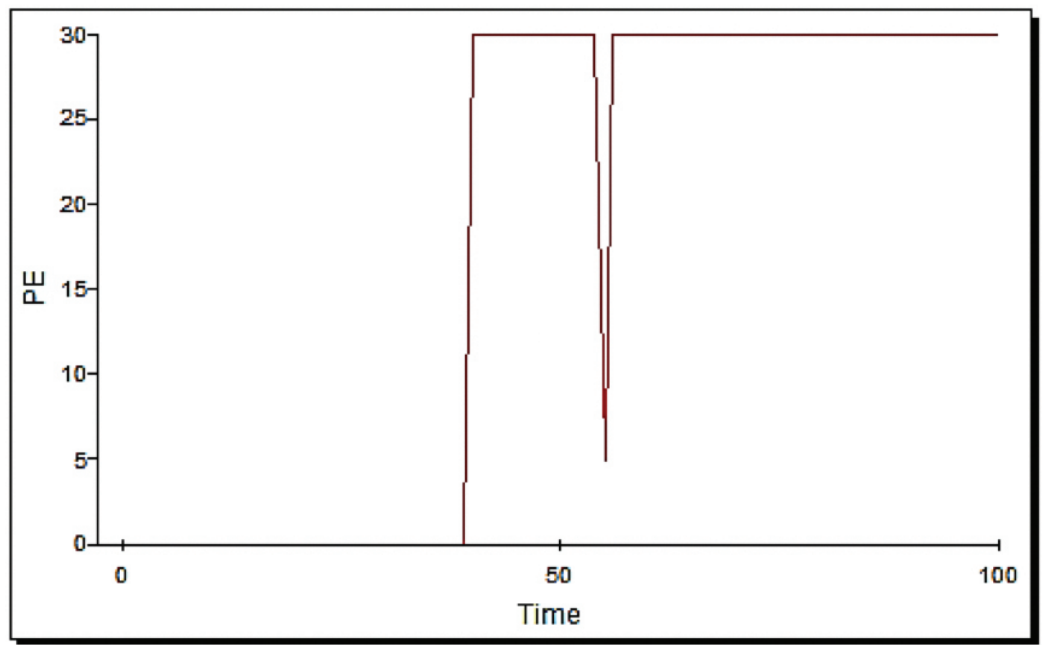

Figure 12.

Relative change of diesel engine power (Authors).

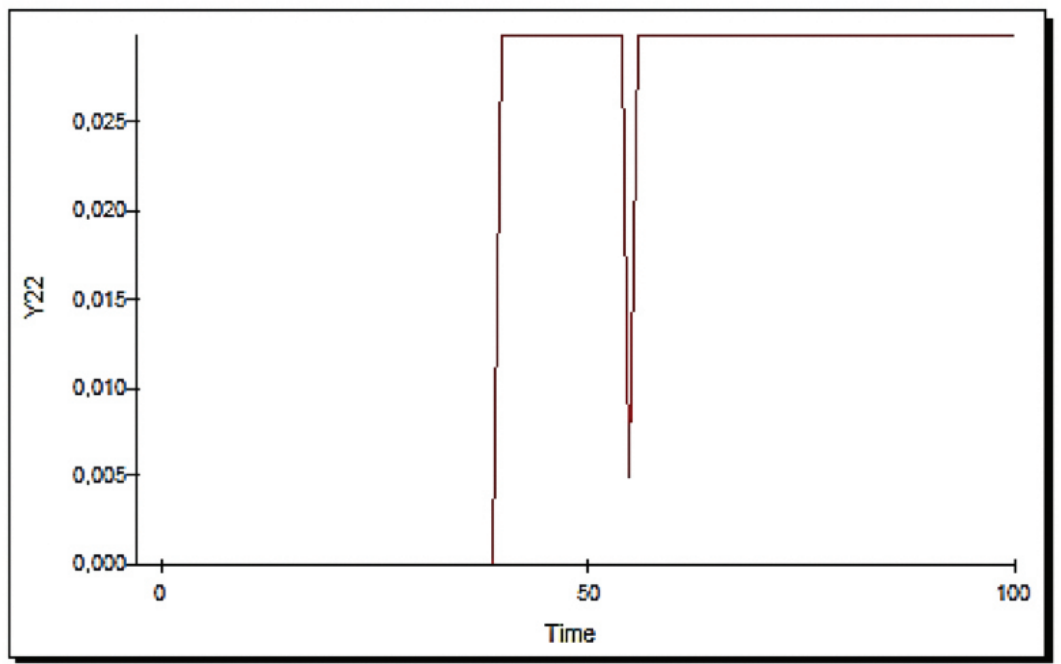

Figure 13

Relative value of HP circuit fresh water temperature change at the outlet of the cooler 2 and engine inlet (Authors). 


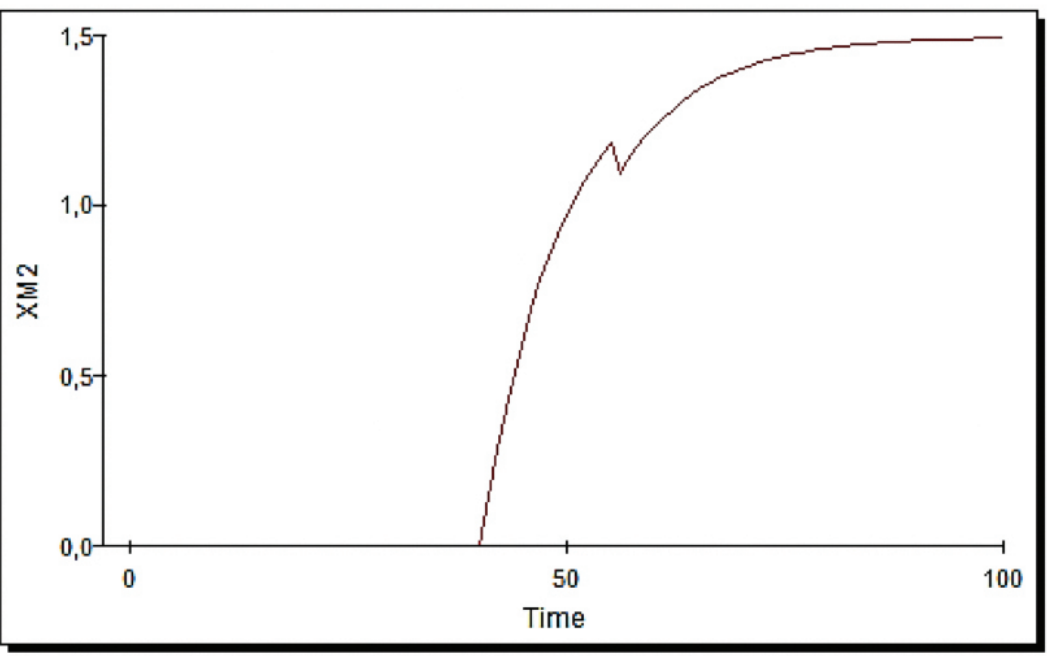

Figure 14.

Relative value of change in water temperature at engine outlet and inlet 2 (Authors).

According to the system-dynamic computer simulation model of the marine diesel engine cooling in Powers simulation language and the adopted initial values of the variables and parameter values given in the model, diagrams and numerical data were obtained according to the given scenario (Marinediesels, 2020). The following is obtained from the diagrams and numerical data:

- the relative change in temperature at the outlet of the engine changes to negligible narrow borders;

- $\quad$ response to change in engine load gives the relative value of change temperatures at the outlet of the cooler 2 .

The obtained numerical data presented in the diagram shows that the described marine diesel engine cooling system with its subsystems is fully functional. The results correspond to the given conditions of the automatic temperature control system (Stanivuk et al., 2019).

\section{CONCLUSION}

Efficient marine propulsion engine cooling significantly affects their economical and reliable operation. Successful cooling depends on a number of different parameters such as freshwater and seawater volumes, freshwater and seawater flow rates, engine inlet and outlet water temperatures, engine load, etc. Due to the complexity and specificity of these parameters, this issue needs to be addressed systematically. The nonlinear dynamic model and the dynamic continuous computer simulation model of the refrigeration system allows the analysis of cause and effect between individual variables and parameters of the system observed. On the same model, heuristic parameter optimization was performed according to the marine diesel engine cooling system and its complexity. The dynamics of behavior and possible optimization were proved. The simulation model made it possible to optimize the parameters of the cooling system and simulate the operating mode according to the desired scenario. Setting the most difficult operating conditions could not be achieved on a real experimental model of a marine diesel engine. The model is easy to use and more cost-effective than an experiment conducted under a real-world system. Applying system dynamics enables the simulation of the operation of the technical system according to the desired scenarios, with the possibility of experimenting with different modes of risky system operations. The simulation model enables obtaining relevant quantitative and qualitative data, complete reproducibility of the simulation experiment and investigating the behavior of the technical system under different exploitation conditions. From an economic point of view, simulation modeling allows the user to create different scenarios under realistic conditions, thus creating prerequisites for prevention and action before possible deviations occur. This is the reason why the application of simulation solutions has become a necessity in the maritime industry, which at the same time requires cost rationalization at all levels while increasing environmental, competitive and safety standards. 


\section{REFERENCES}

Ardakani, D.H. \& Lee, J., 2018. A Minimal-Sensing Framework for Monitoring Multistage Manufacturing Processes Using Product Quality Measurements. Machines, 6(1), p.1. Available at: http://dx.doi.org/10.3390/machines6010001.

Baratta, M. et al., 2005. Analysis of Cyclic Variability in a Bi-Fuel Engine By Means of a 'Cycle-Resolved' Diagnostic Technique, ASME Paper ICEF2005-1214, Fall Technical Conference of the ASME ICED, Ottawa, ON, Canada. Available at: https://doi.org/10.1115/icef2005-1214

Catania, A.E. et al., 2003. A Refined Two-Zone Heat Release Model for Combustion Analysis in SI Engines, JSME International Journal, Series B, Vol. 46, (1), pp. 75-85. Available at:

https://doi.org/10.1299/jsmeb.46.75.

Grzadziela, A., Zateska-Fornal, A. \& Kluczyk, M., 2017. Diagnostic model of fuel installation of marine diesel engine, Transactions on Maritime Science, 6(2). Available at:

https://doi.org/10.7225/toms.v06.n02.001.

Hairuddin, A.A., Wandel, A.P. \& Talal Y., 2013. Effect of different heat transfer models on a diesel homogeneous charge compression ignition engine, International Journal of Automotive and Mechanical Engineering (IJAME) 8, pp. 1292-1304.

Hardenberg, H.O. \& Hase F.W., 1997. An Empirical Formula for Computing the Pressure Rise Delay of a Fuel from Its Cetane Number and from the Relevant Parameters of Direct-Injection Diesel Engines, SAE Technical Paper 790493. Available at: https://doi.org/10.4271/790493.

Heywood, J.B., 2018. Internal Combustion Engine Fundamentals, McGraw-Hill Education, ISBN 978-1-260-11610-6.

Hyundai heavy industries, 2020. MAN B\&W 6 S60 MC-C instruction book, Cheong Dong, Dong-Ku, Ulsan, Korea, general edition 0002.

Jianping, Z., 2011. Computational simulations and applications, InTech, Rijeka, Croatia.

Jurjević, M., 2001. System-dynamic modelling of diesel engine with turbo blower, MA paper, Split.

Kongsberg Maritime, 2015. ERS MAN B\&W 5L90MC-L11 Machinery \& Operation MC90-V, Doc. no.: SO-1342-G2

Lalić, B., 2020. Low speed marine diesel engine modeling for NOx prediction in exhaust gases", Doctoral dissertation, Faculty of Maritime Studies, University of Split.

Lalić, B., Komar, I. \& Nikolić, D., 2014. Optimization of ship propulsion diesel engine to fulfill the new requirements for exhaust emissions, Transactions on Maritime Science, 3(1), pp. 20-31. Available at: https://doi.org/10.7225/toms.v03.n01.003.

Lalić, B., Račić, N. \& Radica, G., 2017. Two-Stroke Low Speed Diesel Engine Simulation Model for NOx Analysis. Transactions on Maritime Science, 6(1), pp.14-23. Available at: http://dx.doi.org/10.7225/toms.v06.n01.002.
Ljubetić, M., 2020. Ship resistance and propulsion, Maritime faculty, Dubrovnik.

Löhner, K., Döhring, E. \& Chore, G., 1956. Temperaturschwingungen an der Innenwand von Verbrennungskraftmaschinen, MTZ Nr. 12.

MAN, 2020. Diesel \& Turbo, MAN B\&W Service Experience letter 2006-2016, 2450 Copenhagen SV, Denmark.

Marine Diesels, 2020. Available at: www.marinediesels.info, accessed on: 14. Sep 2020.

Marinesight, 2019. Available at: www.marinesight.com, accessed on 19 Sep 2019.

Milić, L., 1991. Operation of diesel engines, Maritime faculty, Dubrovnik.

Milić, L., Milić, I., 1995. Fundamentals of automation, Maritime faculty, Dubrovnik.

Munitić, A., 1989. Computer simulation and system dynamics, Brodosplit, Split.

Ozretić, V., 2004. Ship auxiliary machines and devices, Split Ship Management Ltd., Split.

Parra, C.A.F., 2008. Heat Transfer Investigations in a Modern Diesel Engine, Doctoral dissertation, University of Bath Department of Mechanical Engineering, Bath, UK.

Pflaum, W., Mollenhauer, K., 1977. Wärmeübergang in der Verbrennungskraftmaschine, List-Pishinger - Die Verbrennungskraftmaschine, Band 3, SpringerVerlag, Wien, New York.

Przybyla, G., Postrzednik, S. \& Zmudka, Z., 2015. The heat transfer coefficient calculations of internal combustion engine fuelled with natural gas, Scientific Letters of University of Rzeszow Technology - Mechanics, 32(87),pp. 71-80. Available at: https://doi.org/10.7862/rm.2015.8.

Račić, N., 2008. Simulation of marine propulsion system operation with slowspeed diesel engine in difficult conditions, Doctoral dissertation, Technical Faculty, University of Rijeka.

Spitsov, O., 2013. Heat transfer inside internal combustion engine: Modelling and comparison with experimental data, Master's thesis, Lappeenranta University of Technology, Faculty of Technology, Lappeenranta, Finland.

Šretner, J., 1970. Ships' internal combustion engines, Faculty of Naval Architecture, Zagreb.

Stanivuk, T. et al., 2019. System dynamics as the diesel engine cooling system. 19th International Conference "Research and Development in Mechanical Industry" RaDMI-2019, Belgrade, 12-15 September 2019.

Thiessen, F. \& Dales, D., 1986. Diesel fundamentals, Principe and Service, A Reston Book, Prentice-Hall, Englewood Cliffs, New Jersey.

Woodward, J., 1975.Marine gas turbines, New York.

Woodyard, D., 2009. Gas Turbines. Pounder's Marine Diesel Engines and Gas Turbines, pp.829-864. Available at: http://dx.doi.org/10.1016/b978-0-7506-8984-7.00031-x.

Woschni, G., 1970. Die Berechtung der Wandverluste und der thermischen Belastung der Bauteile von Dieselmotoren", MTZ Nr. 12, 491-499. 